\title{
Foraging modes of chinstrap penguins: contrasts between day and night
}

\author{
John K. Jansen*, Peter L. Boveng, John L. Bengtson \\ National Marine Mammal Laboratory, Alaska Fisheries Science Center, National Oceanic and Atmospheric Administration, \\ 7600 Sand Point Way N.E., Building 4, Seattle, Washington 98115-0070, USA
}

\begin{abstract}
Penguins rely on vision to travel and hunt at sea. Vision in marine predators, particularly those hunting phototactic prey under a broad range of light intensities, must be better understood to realize how these species respond to changes in their environment. We studied the effects of daily cycles in light intensity on visual predators by examining the duration and timing of chinstrap penguins' Pygoscelis antarctica foraging trips and the size, composition, and timing of their meals. We used radio telemetry and stomach-contents sampling to study adult penguins that were provisioning chicks during the summers of 1993 and 1994 at Seal Island, Antarctica. The penguins rarely initiated or terminated foraging trips at night, but otherwise varied the timing and duration of trips to sea. Cluster analyses using departure and arrival times revealed 5 distinct modes of foraging: 3 were strictly diurnal (early, mid-, and late) and 2 were partly nocturnal (overnight and extended). Durations of diurnal trips ( 4 to $11 \mathrm{~h}$ ) were shorter than overnight ( 13 to $14 \mathrm{~h}$ ) and extended trips (18 to $22 \mathrm{~h}$ ). Early and middiurnal trips and extended trips were significantly shorter in 1993 than in 1994; late diurnal and overnight trip durations did not differ between years. Diurnal foraging was most common in 1993 , whereas overnight foraging predominated in 1994. Shortened diurnal foraging in 1993 appears to have increased the frequency of diurnal foraging by allowing more parent birds to alternate diurnal trips within a single day and by reducing the incidence of birds extending diurnal foraging through the night. That penguins foraged more frequently by day when permitted by shorter trip durations (in 1993) suggests that they opted to forage diurnally whenever possible. Returning diurnal and overnight foragers had greater than 99 and $74 \%$ Antarctic krill Euphausia superba by weight in their stomachs, respectively. However, overnight foragers also returned with significant amounts of highly digested remains of pelagic fish, suggesting birds were in offshore waters taking fish during the night. In contrast, only 1 out of 40 diurnal foragers from both years combined had evidence of fish. Thus, the daily light cycle affected both the timing and duration of chinstrap penguin foraging as well as the type of prey consumed during trips to sea.
\end{abstract}

KEY WORDS: Diel activity patterns - Diet composition - Foraging trip duration Myctophid fish Ecological monitoring Pygoscelis antarctica - Euphausia superba

\section{INTRODUCTION}

Empirical and experimental evidence points to vision as the primary sense used by birds to negotiate their environment by day and night (reviewed by Martin 1990a, b], even though olfactory and magnetic cues have also proven important (Presti 1985, Verheyden \& Jouventin 1994, Nevitt et al. 1995). The vast majority of the world's bird species are active primarily during the day, and less than $1 \%$ are active entirely at night (Mar-

·E-mail: john.jansen@noaa.gov tin 1990b). Although most seabirds occupy nesting colonies at night, some occasionally or regularly remain at sea (albatrosses: Weimerskirch \& Wilson 1992; storm-petrels: Grubb 1974; shearwaters: Brooke 1990; penguins: Kooyman et al. 1992). Diving seabirds regularly experience less light than surface feeders and there is little evidence that they possess unusual visual capacities (Martin \& Young 1984, but see Bowmaker \& Martin 1985). That visual acuity in submarine hunters changes as a function of solar elevation and prey depth has important implications for understanding the constraints on foraging behavior in penguins. Antarctic penguins are particularly relevant to under- 
standing visual constraints because most occupy an environment characterized by broad ranges of daily light intensities, as well as extreme shifts in daylength.

Foraging activity in many species of penguins has been linked to the daily light cycle. The typical pattern is for most birds to be at sea midday and ashore at night (Adélie penguins Pygoscelis adeliae, Yeates 1971; gentoo penguins $P$. papua and chinstrap penguins $P$. antarctica, Trivelpiece et al. 1986; African penguins Spheniscus demersus, Wilson 1985; emperor penguins Aptenodytes forsteri, Kirkwood \& Robertson 1997; Humboldt penguins S. humboldti, Wilson \& Wilson 1990; Magellanic penguins S. magellanicus, Scolaro \& Suburo 1994; rockhopper penguins Eudyptes chrysocome, Wilson et al. 1997). Some species, however, dive at night (macaroni penguins E. chrysolophus, Croxall et al. 1988; king penguins A. patagonicus, Kooyman et al. 1992), despite recent evidence suggesting that when foraging nocturnally, penguins have lower prey capture rates than when feeding during the day (Wilson et al. 1993, Pütz \& Bost 1994, Wilson 1995, Wilson \& Wilson 1995). A recent model of aquaiic visudi feeding indicated that dally variations in light intensity, and thus visual range, may be more important to predator feeding than typical variations in prey abundance (Aksnes \& Giske 1993).

Marked light-dependent rhythms in penguin foraging activity (see Wilson et al. 1989, Williams \& Rothery 1990, Golombek et al. 1991) suggest that the timing of trips to sea is an important factor in foraging success. The synchronization of a colony's foraging patterns in response to environmental cues may enhance prey searching and capture through communication about feeding conditions (Ward \& Zahavi 1973, Brown 1986) and group foraging, a widespread behavior in penguins (Ainley 1972, Broni 1985, Wilson et al. 1986a, Norman \& Ward 1993). Despite evidence that changes in light affect the timing and efficiency of penguin foraging, remarkably few studies have shown more than gross trends in the activity of penguin rookeries in relation to light cycles (Wilson et al. 1989, Williams \& Rothery 1990). Nor has much research focused on the potential constraints of variable light for visually-hunting penguins whose daily foraging budget may include nocturnality at sea.

In this study, we examined the timing and duration of foraging trips taken by chinstrap penguins at colonies where adults are known to spend time at sea overnight (Bengtson et al. 1993). Because penguins relying on vision may be less effective hunters at night, we predicted that the birds could enhance foraging by feeding diurnally whenever possible or by adopting alternative feeding tactics at night. During our study, penguins were rearing small chicks and the sun was below the horizon for at least 6 h per night. By evaluat- ing their diet, we were able to compare chinstrap penguins foraging under different light regimes and determine whether there may be energetic consequences of varying light intensity. As part of a long-term study of chinstrap penguins and their prey, the goals here were 2-fold: to understand the basic foraging patterns of a marine predator in relation to a fundamental physical variable, light, and to build upon a framework from which future studies will be better able to distinguish predator behavior caused by changes in marine prey resources from that due to phylogenetic constraints, such as visual limitations.

\section{METHODS}

We studied chinstrap penguins at Seal Island, South Shetland Islands, Antarctica $\left(60^{\circ} 59^{\prime}\right.$ S, $55^{\circ} 23^{\prime}$ W; Fig. 1) during the austral summers of 1993 and 1994 at 2 breeding colonies: North Cove, a colony of approximately 900 nests located at the edge of a large intertidal pool about $70 \mathrm{~m}$ from the open sea, and Colony 72, with approximately 400 nests located on a $300 \mathrm{~m}$ long beach (Fig. 1, inset).

Foraging activity. The presence or absence of adult chinstrap penguins provisioning chicks at North Cove colony was recorded using radio telemetry from 9 to 22 January 1993 and from 8 to 19 January 1994. The end date in both years was determined by the beginning of the post-guard phase, the point at which parents leave chicks unattended in the colony and are able to forage independently. Radio transmitters (Advanced Telemetry Systems, Isanti, MN, USA; reference to trade name does not imply endorsement by National Marine Fisheries Service, NOAA) were deployed on the departing adult from each of 80 nests $(1993, n=40,1994, n=40)$ after a nest relief had occurred so as to minimize disturbance of the mate on the nest. The foraging activity of instrumented penguins was measured beginning $1 \mathrm{~d}$ after all 40 penguins were fitted with transmitters; this delay was an effort to reduce the effects that handling the birds and disturbing the colony may have had on foraging behavior. Radio transmitters $(1.35 \mathrm{~cm}$ diameter, $6.8 \mathrm{~cm}$ length) were attached with epoxy and a plastic cable tie to feathers at the middle of each penguin's back, posterior to the point of the bird's maximum girth to minimize drag (Bannasch et al. 1994), with the whip antenna trailing behind. The instruments were wedge-shaped at the anterior end, had a frontal cross-sectional area of $1.4 \mathrm{~cm}^{2}$ and a $28.5 \mathrm{~cm}$ antenna, and weighed $20 \mathrm{~g}$. Attachment of this type of transmitter ( $<1 \%$ of the bird's cross-sectional area) on chinstrap penguins at Seal Island had no measurable effect on duration of foraging (Croll et al. 1996). However small, any crag caused by these instruments 
Fig. 1 Location of Seal Island within the Antarctic Peninsula region. The dotted line indicates the $1000 \mathrm{~m}$ isobath. Inset shows the locations of North Cove colony and Colony 72 in relation to other chinstrap penguin colonies on Seal Island

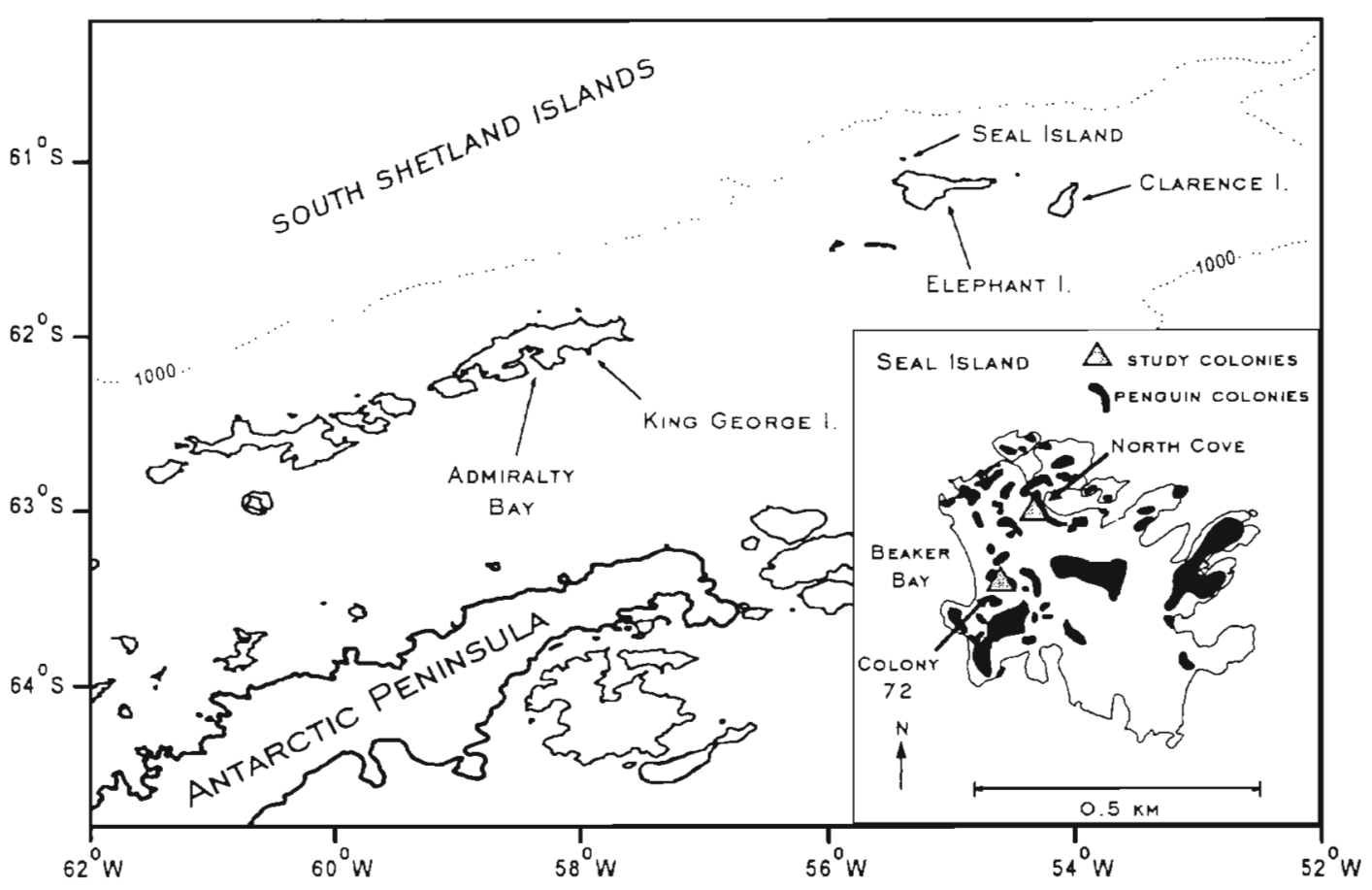

would have energetic and possibly behavioral consequences (Wilson et al. 1986b, Culik et al. 1994).

The timing of departures from and arrivals to the island were monitored by an automated receiving system (Advanced Telemetry Systems) that sampled and recorded the presence or absence of each radio-tagged bird during a $10 \mathrm{~s}$ interval every $15 \mathrm{~min}$. Departure and arrival times were used to determine foraging trip durations, which were defined as the actual time spent in the water; due to the island's topography, penguins nesting at North Cove entered and exited the water in the immediate vicinity of the receiver. All arrival and departure times were converted into local apparent times (i.e. 12:00 h occurs at the sun's zenith). Foraging activity patterns determined for a particular date included only those trips initiated on that day. Observations confirmed that all nests included in the sample had at least 1 chick during the study period in each year. Previous analyses indicated that there were no differences in foraging trip duration between penguins rearing 1 versus 2 chicks (Meyer et al. 1997).

Food load sizes and diet composition. Diet composition and the mass of food brought ashore were determined by extracting stomach contents from non-instrumented penguins at Colony 72 using a lavage technique (Wilson 1984). Birds that had just completed a foraging trip were captured after they reunited with their mates at the nest but before feeding their chick(s). In 1993, each bird's sample was collected in a single bucket, whereas in 1994, the digested portion (i.e. individual prey in pieces) was collected in a separate bucket from the mostly intact stomach contents, which were always egested first. During 1993, birds were lavaged 4 times unless clear water was recovered in fewer repetitions. In 1994, birds were always lavaged 4 times; we discovered that even though birds may have seemed empty after a second or third lavage, additional food could sometimes be extracted subsequently. This procedure provided greater uniformity in lavaging and reduced bias in recovering hard parts that could be present at the bottom of the stomach and therefore more difficult to extract. Material recovered in the fourth lavage was always slight and we judged that any gains obtained from additional lavages would not justify further disturbance to the bird. Five birds in 1993, all arriving in the evening, appeared to have empty stomachs and were lavaged only 3 times. One bird in 1994 showed signs of distress and was released after the third lavage.

Stomach samples were collected from 5 different birds every 5-day period throughout chick provisioning $(1993,6$ January to 3 February, $n=35 ; 1994,8$ January to 12 February, $\mathrm{n}=40$ ). Birds were sampled as they arrived in the morning $107: 00$ to $09: 00 \mathrm{~h} ; 1993, \mathrm{n}=$ $15 ; 1994, \mathrm{n}=20)$ or in the evening $(17: 00$ to $19: 00 \mathrm{~h}$; 1993, $n=20 ; 1994, n=20$ ), alternating between 5 -day periods. Samples were drained, weighed, sorted into primary prey categories (i.e. crustaceans, fish, and squid), and then reweighed to determine percent composition. Because samples in 1994 were sorted before weighing, more water may have drained out during sorting, possibly biasing these samples toward slightly lighter masses compared with 1993. Soft parts, consisting primarily of euphausid krill and fish, were pre- 
served in a $10 \%$ formalin solution and stored for subsequent analyses of size, sex, and reproductive status. Hard parts, consisting of fish otoliths and squid beaks, were stored in isopropyl alcohol, dried, and later enumerated and identified to species. Prey parts were assumed to derive from the most recent foraging trip an assumption supported by the results (see below).

Statistical procedures. Two phases of cluster analyses were used to identify patterns in the timing of departures from and arrivals to the island. First, agglomerative hierarchical clustering, which combined foraging trips into clusters that were then progressively combined with other similar clusters, was used to calculate a coefficient of heterogeneity (Ward's method, SPSS Inc. 1993, Hair et al. 1992). A sharp increase in this coefficient indicated that clusters combined subsequently were of distinctly different departure and/or arrival times. This initial procedure allowed determining the number of clusters and the location of each cluster's center, both of which were necessary for the final analysis. Using each cluster's center as a seed, a non-hierarchical clustering method 'fine-tuned' the results by allowing the switching of cluster membership through sequential iterations of the clustering algorithm (parallel-threshold procedure; 'quick cluster', SPSS Inc. 1993, Hair et al. 1992)

We compared durations of trips using 2-way analyses of variance (ANOVA) with year and trip type as the categorical variables. Count data on the frequency of daily foraging patterns and the incidence of fish in penguins' diet were analysed using multiway contingency tables (i.e. G-test). In these analyses, means and count data for each penguin's trip durations and/or daily patterns were not necessarily independent. However, because the null hypotheses were extremely improbable (i.e. $10^{-3}<\mathrm{p}<10^{-9}$ ), reducing the degrees of freedom to levels commensurate with the number of birds for any significant test did not increase $p$ beyond the 0.05 level. When individual birds were included more than once in a sample, summary statistics (i.e. trip duration and percent frequency of daily foraging patterns) were calculated using the means from each individual bird.

\section{RESULTS}

\section{Characteristics of foraging trips}

During chick-brooding in 1993 and 1994, the frequency distributions of arrival and departure times of radio-tagged chinstrap penguins were approximately bimodal (Fig. 2). The hierarchical cluster analyses of both years' data, using the timing of departures and arrivals as variables, confirmed the presence of at least

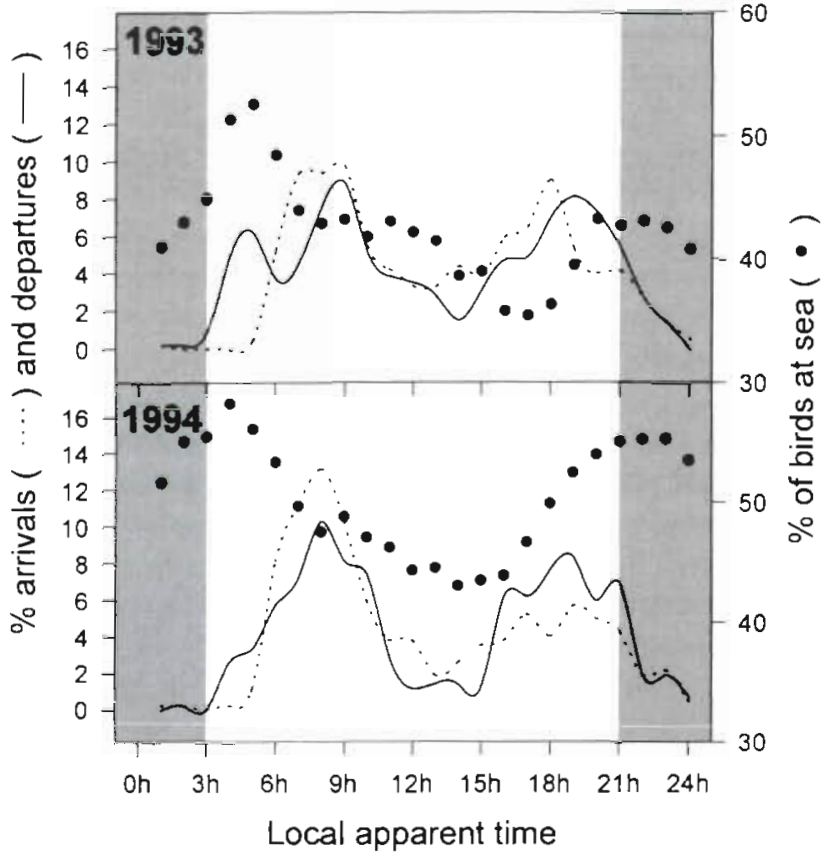

Fig. 2. Pygoscelis antarctica. Frequency distribution of chinstrap penguins departing from and arriving at North Cove colony in relation to time of day for 1993 and 1994 (spline curves). Dots show the percentage of birds that were at sea within the respective hourly intervals averaged across all days of the study period. Shaded regions indicate periods when the sun was below the horizon

2 clusters representing 2 basic modes of foraging: those trips that were initiated and completed within the same day (i.e. were entirely diurnal) and those that were terminated the day following departure (i.e. were at least partially nocturnal). Multimodal frequency histograms of departure time for both diurnal (trimodal) and overnight (bimodal) clusters in 1993 and 1994 indicated these modes were composed of additional foraging patterns that required further differentiation (see Schreer \& Testa 1995). Plots of arrival time appeared unimodal and therefore were not useful in discriminating diurnal and overnight sub-groups. After partitioning all modes hierarchically, the resulting cluster centers (i.e. 3 during the day, 2 overnight) seeded the final nonhierarchical cluster analysis which produced 5 distinct patterns of foraging for both 1993 and 1994 (Fig. 3). The timing and durations of the 5 derived trip types for each year, defined as early diurnal $\left(D_{e}\right)$, middiurnal $\left(D_{m}\right)$, late diurnal $\left(D_{1}\right)$, overnight $(O N)$, and extended (EX), are summarized in Fig. 4

In both years, birds rarely traveled to and from the island during the hours of darkness (Figs. $2 \& 3$ ). Early diurnal foragers began departing just prior to sunrise, followed about 1 to $2 \mathrm{~h}$ later by mid-diurnal foragers. Late diurnal foragers began departing about $6 \mathrm{~h}$ later on trips which terminated just before sunset. The first 


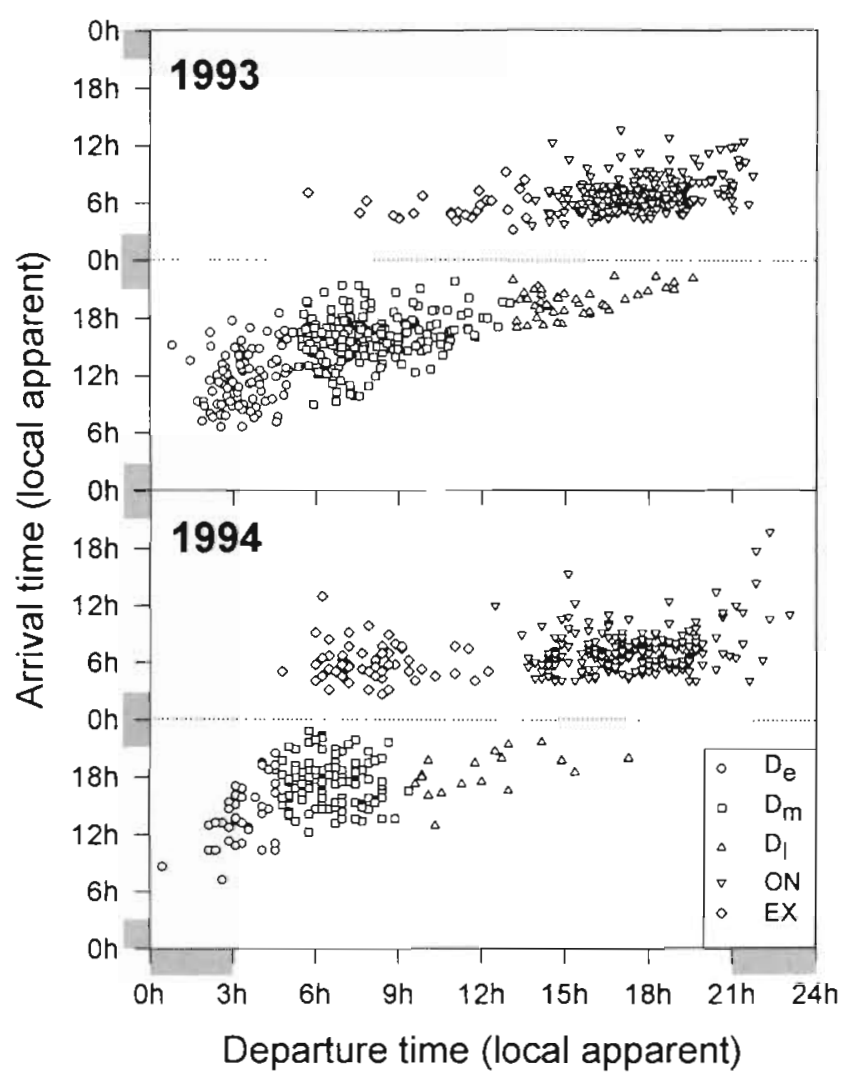

Fig. 3. Pygoscelis antarctica. Individual foraging trips by departure and arrival time for 1993 and 1994. Each aggregation of different symbols signifies distinct clusters of either diurnal ( $D_{e}$, early diurnal; $D_{m}$ mid-diurnal; $D_{1}$, late diurnal) or overnight ( $O N$, overnight; $E X$, extended) foraging trips (see symbol legend). Shading on the time axes indicates periods when the sun was below the horizon. Dotted lines separate trips completed in one day (lower) from those not completed until the following day (upper) in each year penguins to depart on overnight trips (i.e. extended trips) did so amidst the morning diurnal-trip departures. The modal departure time of overnight foragers was during the early evening before sunset. Early morning overlap of different trip types (i.e. $D_{e}, O N$ and EX) resulted in peak percentages of birds at sea at 03:00 to $05: 00 \mathrm{~h}$, whereas overlapping nest exchanges at $07: 00$ to $09: 00 \mathrm{~h}$ and $14: 00$ to $17: 00 \mathrm{~h}$ corresponded to the minimum proportion of birds at sea (Fig. 2).

Eighty percent of late diurnal foraging trips represented penguins' first trip of the day and the remaining represented second trips of the day. Most penguins in the former category postponed foraging because they were presumably waiting to be relieved by mates that had embarked on earlier diurnal trips. Early and late diurnal foragers were apparently those birds from nests where mates alternated diurnal trips on a given day. In these instances, both mates subsequently remained ashore through the night, or the mate that foraged first then departed on its second trip of the day which spanned overnight. Virtually all birds (93 to $99 \%$ ) that departed in the evening on overnight trips had not foraged previously that day.

Differences in trip duration between years depended on the type of trip in question (year by trip-type interaction, $\left.F_{4,290}=4.2, p=3 \times 10^{-4}\right)$. Multiple comparisons using the Tukey HSD procedure indicated that early and mid-diurnal foraging trips were significantly shorter in 1993 than in 1994 (Fig. 4 ; $\mathrm{D}_{e}, \mathrm{p}=2 \times 10^{-4} ; \mathrm{D}_{\mathrm{m}}$, $p=3 \times 10^{-6}$ ), but that late diurnal trips did not differ statistically between years ( $p=0.55$ ). Extended trips were also shorter in 1993 compared with 1994 ( $p=8 \times$ $\left.10^{-6}\right)$, but overnight foraging trips were not different $(\mathrm{p}=0.87)$.
Fig. 4. Pygoscelis antarctica. Timing and duration of diurnal $\left(\mathrm{D}_{\mathrm{e}}\right.$, early diurnali $D_{m}$ mid-diurnal; $D_{1}$, late diurnalj and overnight foraging trips (ON, overnight; EX, extended) for 1993 and 1994. Numbers in bars indicate mean duration of trip; standard deviation in parentheses. Arrival and departure times and trip durations were averaged across individual-bird means for each trip type. Numbers of trips and penguins exhibiting specific trips are shown in the right-hand columns. Shading indicates periods when the sun was below the horizon. Asterisks next to bars in 1993 denote trip types that were significantly $(p<0.05)$ shorter than in 1994

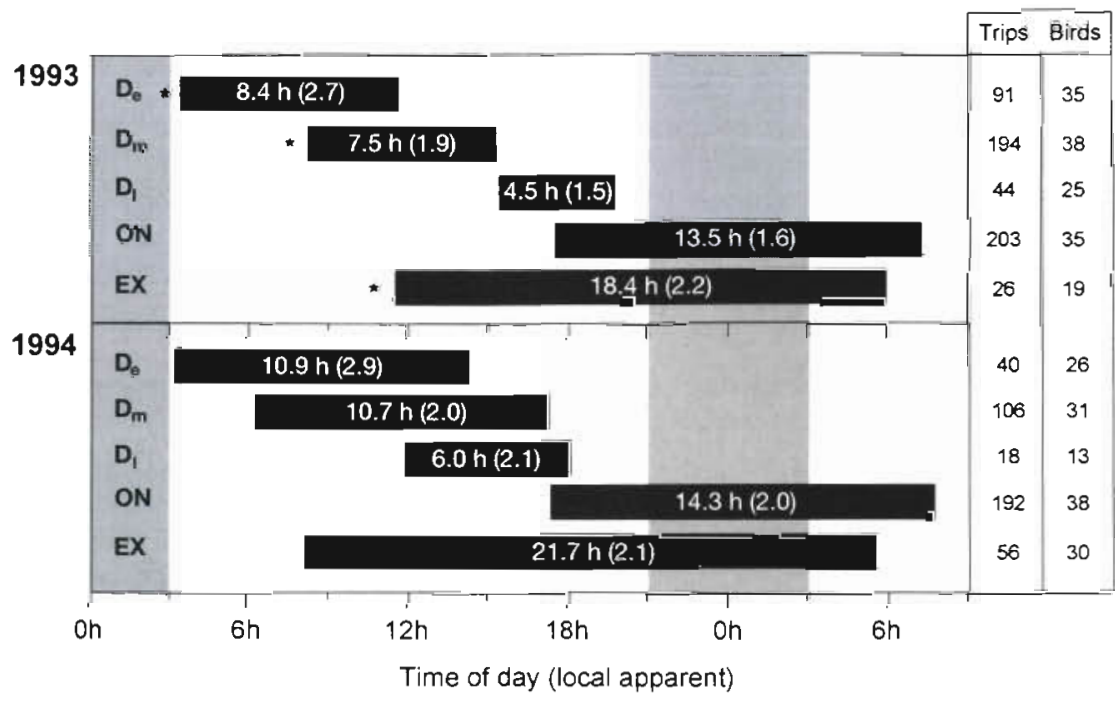


Table 1. Pygoscelis antarctica. Percent frequency of occurrence of daily foraging patterns $\left(D_{e}=\right.$ early diurnal, $D_{m}=$ mid-diurnal, $\mathrm{D}_{1}=$ late diurnal, $\mathrm{ON}=$ overnight, $\mathrm{EX}=$ extended, $2 \mathrm{D}=2$-diurnal, $\mathrm{D}-\mathrm{ON}=1$ diurnal/1 overnight, $\mathrm{NT}=$ no trip initiated] of chinstrap penguins during chick-brooding. Bird-days represent the total number of days on which individual birds were monitored (e.g. 40 birds each being monitored over a period of $14 \mathrm{~d}=560$ bird-days)

\begin{tabular}{|c|c|c|c|c|c|c|c|c|c|c|c|c|}
\hline \multirow[t]{3}{*}{ Year } & \multirow{3}{*}{$\frac{\mathrm{n}}{\text { (bird-days) }}$} & \multicolumn{10}{|c|}{ - Daily foraging activity patterns (\%) - } & \multirow{3}{*}{$\begin{array}{l}\text { Trips per } \\
\text { bird-day }\end{array}$} \\
\hline & & \multicolumn{4}{|c|}{ Diurnal } & \multicolumn{3}{|c|}{ Overnight } & \multicolumn{2}{|c|}{ Multiple trips ${ }^{a}$} & \multirow[t]{2}{*}{$\mathrm{NT}$} & \\
\hline & & $\mathrm{D}_{e}$ & $\mathrm{D}_{m}$ & $\mathrm{D}_{1}$ & All & ON & $\mathrm{EX}$ & All & $2 \mathrm{D}$ & D-ON & & \\
\hline 1993 & 560 & 9 & 32 & 6 & 47 & 32 & 2 & 34 & 2 & 7 & 10 & 1.00 \\
\hline 1994 & 468 & 8 & 23 & 3 & 34 & 41 & 12 & 53 & $<1$ & $<1$ & 13 & 0.89 \\
\hline
\end{tabular}

\section{Daily foraging patterns}

Chinstrap penguins initiated 0,1 , or 2 foraging trips on any given day, but the relative frequency of the different patterns differed between the 2 years of this study (Table 1; likelihood ratio test: $G=92.3 ; \mathrm{p}<10^{-9}$; $\mathrm{df}=5 ; \mathrm{n}=1028$ bird-days). A single diurnal trip was most common in 1993, whereas overnight trips predominated in 1994. Extended trips were about 6 times more common in 1994 than in 1993 (2 vs $12 \%$ of birddays). Although it was uncommon for a bird to initiate 2 trips in a day, this pattern was considerably more frequent in 1993 than 1994, contributing to an overall higher trip frequency in 1993 (Table 1). Birds that initiated 2 trips in one day did so either by taking 2 diurnal trips (i.e. early and late diurnal trips) or by combining 1 early diurnal with 1 overnight foraging trip. Birds completing 2 diurnal trips departed on the second trip within about $3 \mathrm{~h}$ of terminating the first, probably not sufficient time for mates to take a trip in between. Individual penguins refrained from initiating foraging on an average of $\sim 1.5 \mathrm{~d}(\sim 10 \%$ of days) during the study period in each year.

\section{Diet of diurnal and overnight foragers}

In 1993 and 1994, all chinstrap penguins returning in the morning (i.e. overnight trips) and evening (i.e. diurnal trips) had predominantly Antarctic krill in their stomachs (Table 2). Fish was more likely to occur in the stomachs of overnight than diurnal foragers $(G=45.6$, $\left.\mathrm{df}=1, \mathrm{p}<10^{-7}\right)$ : fish remains were found almost exclusively in birds that had been feeding overnight (e.g. only 1 diurnal sample in 1994 had evidence of fish). The predominance of fish in overnight versus diurnal foragers did not change between years (type-of-forager by year interaction: $G=0.20, \mathrm{df}=1, \mathrm{p}=0.65$ ). Fish occurred more frequently in the samples during 1994 than in $1993(G=4.12, \mathrm{df}=1, \mathrm{p}<0.05)$ and were also more abundant numerically (comparison of number of otoliths between years: $t=1.97, \mathrm{df}=23, \mathrm{p}=0.035$, Table 2). Remnants of squid and amphipods were observed only rarely, composing $<1 \%$ of the total mass of the diet samples. The virtual absence of otoliths and other hard parts in diurnal foragers, even though some of these penguins probably foraged overnight the previous trip (i.e. birds were not strict specialists), indi-

Table 2. Pygoscelis antarctica. Diet mass and composition and frequency of occurrence of fish in the diet of chinstrap penguins sampled after returning from diurnal (D) and overnight (ON) foraging trips. Intact and digested portions of the diet samples were examined separately in 1994 only. na: not applicable; t: trace, i.e. no flesh was recovered, only otoliths and eye lenses were found (weight $<1 \%$ ). Unidentifiable prey rounds out any remaining proportions of diet composition by weight

\begin{tabular}{|c|c|c|c|c|c|c|c|c|c|c|c|c|c|}
\hline \multirow[t]{3}{*}{ Year } & \multirow{3}{*}{$\begin{array}{l}\text { Type of } \\
\text { forager }\end{array}$} & \multirow[t]{3}{*}{$\mathrm{n}$} & \multirow{3}{*}{$\begin{array}{l}\text { Mean } \\
\text { weight } \\
(g)(S D)\end{array}$} & \multirow{3}{*}{$\begin{array}{l}\% \text { intact } \\
\text { (by wt) }\end{array}$} & \multicolumn{6}{|c|}{$\%$ composition by weight } & \multirow{3}{*}{$\begin{array}{c}\% \text { of samples } \\
\text { with evidence } \\
\text { of fish }\end{array}$} & \multirow{2}{*}{\multicolumn{2}{|c|}{$\begin{array}{l}\text { No. of } \\
\text { otoliths }\end{array}$}} \\
\hline & & & & & & Intact ${ }^{2}$ & & & igeste & & & & \\
\hline & & & & & Krill & Fish & Squid & Krill & Fish & Squid & & Mean $^{b}$ & Range \\
\hline \multirow[t]{2}{*}{1993} & $\mathrm{D}$ & 20 & $356(146)$ & na & 100 & - & - & na & na & na & 0 & - & - \\
\hline & ON & 15 & $407(148)$ & na & 96 & $4^{c}$ & - & na & na & na & 53 & 11 & $5-33$ \\
\hline \multirow[t]{2}{*}{1994} & $\mathrm{D}$ & 20 & $595(207)$ & 62 & 100 & $\mathrm{t}$ & - & 98 & $\mathrm{t}$ & - & 5 & 6 & na \\
\hline & ON & 20 & $499(140)$ & 60 & 96 & 3 & - & 42 & 43 & $<1$ & 85 & 45 & $1-180$ \\
\hline
\end{tabular}


cates that fish remains are not retained in the stomach from one trip to the end of the next.

Fish recovered from overnight foragers were never intact and usually occurred in the form of bones, otoliths, and small pieces of flesh. In both years, the fish prey of overnight foragers were primarily myctophids $(95 \%)$, such as Electrona antarctica, E. carlsbergi, Gymnoscopelus nicholsi, and Krefftichthys anderssoni and less commonly $(5 \%)$ the paralepidid Notolepis coatsi. During lavaging, pieces of fish appeared only after fresher krill had been regurgitated. The appearance of fish usually indicated food had come from the bottom of the stomach as subsequent lavaging produced little additional prey. It was apparent any mixing that may have occurred in the stomach during lavaging was not sufficient to obscure the stratification of prey in the gut. Whereas in 1993 only 1 sample from an overnight forager contained parts of fish flesh large enough to be recovered (286 g), 15 samples in 1994 contained between 2 and $347 \mathrm{~g}$ of fish flesh. Fish composed at least one-half of the identifiable prey (by weight) in the digested samples from overnight foragers in 1994 (Table 2).

The timing of foraging trips (diurnal vs nocturnal) had no significant effect on the mass of food brought ashore in either year (2-way ANCOVA with day of the year as the covariate: $F_{1,74}=0.186, p=0.67$ ). However, the mean weight of samples was heavier in 1994 than in $1993\left(F_{1,74}=15.61, \mathrm{p}<0.001\right)$. The increased food mass in 1994 may have been the result of larger food loads in diurnal than in overnight foragers, but the trend was not quite significant (year by trip-type interaction, $F_{1,74}=2.86, \mathrm{p}=0.09$ ).

\section{DISCUSSION}

\section{Arrivals and departures at night}

Occasional nocturnality in otherwise diurnal birds is relatively common (Martin 1990a), but how these birds cope with the constraints of darkness is not well known. The restricted lifestyle imposed on truly nocturnal birds (Martin 1986) suggests that a high degree of specialization is required to persist in a low-light environment. Still, birds that are primarily diurnal commonly travel long distances at night, albeit by flying at altitudes well away from obstacles (Martin 1990b). Chinstrap penguins at Seal Island, although known to dive during nocturnal excursions to sea (Bengtson et al. 1993), apparently lack the ability or motivation to transit the coastline during the darkest hours of the night. The paucity of arrivals to and departures from North Cove between 22:00 and 02:00 h suggests that light intensity restricts the timing of movements to and from the island. It is noteworthy that regardless of the behavioral context in which darkness occurs (e.g. active at sea or relatively inactive at the nest) the same reluctance to transit to/from the island is observed. Because penguins are active at sea during the night, their reluctance to attempt a landing is presumably not governed strictly by a light-mediated endogenous clock (see Cockrem 1990). This avoidance may instead reflect an underlying behavioral adaptation to other environmental constraints, such as risk of predation or lack of prominent visual cues for navigation.

Leopard seals Hydrurga leptonyx hunt penguins at Seal Island (authors' pers. obs.) and may influence the number of trips taken by adults provisioning chicks (Chappell et al. 1993). Chappell et al. (1993), who estimated that $11 \%$ of breeding Adélie penguins at Palmer Station were eaten annually by leopard seals, calculated the risk of Adélie mortality by predation at $0.4 \%$ per trip, a substantial risk when integrated over the breeding season. The impact of leopard seal predation on breeding penguin populations elsewhere was deemed minimal (e.g. $2.4 \%$ per annum, MüllerSchwarze $1984 ; 2.7 \%$, Rogers \& Bryden 1995) or inconsequential (e.g. 2 kills per 13000 birds observed in 120 h over 20 d at 3 rookeries, Hofman et al. 1974; 0 kills per 50000 birds over 21 d, Müller-Schwarze \& Müller-Schwarze 1975).

The timing of leopard seal predation on penguins also appears variable between sites, although detailed information on diel patterns in hunting behavior is sparse. Observations at several penguin breeding sites are difficult to interpret. Different studies have concluded that leopard seals exhibit no diel rhythm in hunting behavior (Cape Crozier, Penney \& Lowry 1967); are primarily in the water at night (Ross Island, Müller-Schwarze 1971); haul out midday (Palmer Station, Hofman et al. 1974); or capture penguins only during the day and haul out during the night (Elephant Island, Conroy et al. 1975). At Seal Island, leopard seals were observed consuming penguins during the day primarily at Beaker Bay (Fig. 1; Lisa M. Hiruki, National Marine Mammal Laboratory, Seattle, WA, USA, unpubl. data), an area transited by as many as 14000 birds daily (i.e. 280001 -way transits). Only 4 of 42 penguin captures observed during 1987-1995 occurred at North Cove, which encompasses coastline transited by fewer than 5000 birds per day. A distinct peak in observed predation (i.e. between 08:00 and 21:00 h) occurred at $\sim 17: 00 \mathrm{~h}$ which corresponds closely to the evening peak in birds transiting the coast (Fig. 2). Penguins at Seal Island may avoid the coastline at night in part because of an increased predatory threat, but the variable nature of leopard seal behavior and impacts - even though penguins show distinct foraging activity patterns (see references above) - 
suggests that more predictable factors may constrain their behavior.

A constraint on penguin orientation in an environ. ment with few visual cues may restrict nocturnal movements to and from Seal Island. Unobscured sunlight was necessary for Adélie penguins to navigate accurately to the ice edge in the Ross Sea (Emlen \& Penney 1966), even though the use of magnetic fields by birds to navigate is also generally accepted (reviewed by Presti 1985 and Moore 1987). Considerable evidence, however, indicates that visual cues are equally or more important than magnetic fields for initiating and maintaining a course in birds migrating by day and night (Martin 1990b and references therein). Further, reduced light is likely to impose limitations on the ability of penguins to negotiate the complex and potentially hazardous coastline of Seal Island (i.e. heavy surf along rocky bluffs and shoreline). That some commuting penguins are injured during periods of intense surf, even during daylight (authors' pers. obs.), confirms there are risks associated with crossing the intertidal zone. If visual acuity in penguins is reduced at night, it could further limit their ability to transit the shoreline safely. Spatial resolution in birds at low light levels is unknown (except for one species of owl; Fite 1973). On theoretical grounds, however, it is understood that the vertebrate eye is incapable of a high degree of spatial resolution at the lowest environmental light intensities (Snyder et al. 1977). Martin (1990b) concluded that birds migrating at night, even under maximum moonlight, were able to detect only the grossest details of their environment. The light gathering capacity and visual sensitivity of the penguin eye fall within the range typically found in mammals and birds (Martin \& Young 1984). Thus, we expect that darkness impacts the ability of chinstrap penguins to navigate the near featureless environment offshore and the precipitous wave-battered coastlines commonly encountered near colony sites.

\section{Timing and frequency of foraging}

The periodic and synchronized nature of the telemetry data suggests that changing light intensity affects chinstrap penguins' foraging trip departures and arrivals. Specifically, the close correspondence between early diurnal departures and sunrise indicates that birds that spent the night ashore responded to increasing morning light; later modes of diurnal foraging indicate that other birds delayed departures to wait for a mate's arrival. Relatively synchronous arrivals probably reflect the combined effects of changing light intensity and similar trip durations by individuals.
Among birds at sea, increasing light intensity may trigger continued foraging. Because birds returned from overnight trips about $3 \mathrm{~h}$ later than birds departing at sunrise, it is clear that birds were not simply waiting offshore for light intensity to increase before attempting to land. Changes in light intensity also elicit vertical migrations in krill swarms. Antarctic euphausiids sink and form dense concentrations during the day and rise to the surface and disperse at night (Kalinowski \& Witek 1980, Everson 1982, Everson \& Murphy 1987, Ringelberg 1995), although diel patterns in krill depth and density have not always been observed (Miller \& Hampton 1989). Even though krill become less available to diving predators as they gradually descend at sunrise, rapidly increasing light intensity may provide a narrow 'window' when visual hunting could actually be enhanced. In both years, the daily peak in proportion of birds at sea occurred just after sunrise (Fig. 2). Termination of continuous nest attendance during the post-guard phase in chinstrap penguins at Seal Island coincided with a shift to diurnal foraging with peak departures occurring at or before sunrise (Jansen 1996). Moreover, penguin studies that examined the actual timing of prey capture during overnight trips (Wilson 1995) or trips longer than $3 \mathrm{~d}$ (Wilson et al. 1993, Pütz \& Bost 1994) indicated enhanced foraging effort and success at dawn and dusk.

The durations of foraging trips on a particular day affect whether mates predominantly alternate diurnal trips (i.e. both mates spend the night ashore), as may have occurred in 1993, or alternate diurnal with overnight foraging, a pattern more apparent in 1994 Shorter diurnal foraging trips early in the day in 1993 ( $\sim 8 \mathrm{~h}$ ) apparently allowed both members of more pairs to forage exclusively during a limited period of day light ( $18 \mathrm{~h}$ ), causing a decrease in overnight foraging. Longer diurnal foraging trips in $1994(\sim 11 \mathrm{~h})$ would preclude more parents from each completing diurnal trips within the same daylight period (i.e second trips from such nests occurred later and could not be completed before the 'transit window' closed). That birds foraged more often during the day in 1993, when diurnal trip durations were generally shorter, suggests that birds were selecting the hours of daylight for foraging whenever possible. In some years, overnight foraging could be a favored strategy. The 2 years reported here, however, suggest that overnight trips can be the consequence of later nest reliefs (i.e longer trips by the nest mate)

Similar to penguins at Seal Island, brooding chinstrap penguins at nearby Elephant Island $\left(61.2^{\circ} \mathrm{S}\right)$ exhibited a bimodal pattern of departures $(04: 00 \mathrm{~h}$ and $12: 00 \mathrm{~h}$ ) and arrivals (10:00 h and 19:00 h) (Conroy et al. 1975). Birds that stayed at the nest with their mates overnight departed just after sunrise, supporting the 
role of light as an important controlling factor. However, the paucity of evening departures (i.e. most nests were occupied by pairs overnight), coupled with midday nest exchanges (see Figs. $3 \& 5$ in Conroy et al. 1975), suggests shorter diurnal trips and fewer birds foraging overnight at Elephant Island than at Seal Island. These differences in foraging may have resulted from contrasting prey availability. Enhanced prey access could have shortened the typical daily foraging cycle at Elephant Island, allowing both mates to feed diurnally.

\section{Light-dependent differences in diet}

The stark contrast between the fresh krill recovered first and the digested fish and krill recovered last from penguins that foraged overnight indicates fish were taken early during foraging trips, whereas krill were taken during feeding periods throughout trips. Freeranging African and captive gentoo penguins are known to digest fish down to bones and otoliths within 10 to $16 \mathrm{~h}$ (Wilson et al. 1985, Gales 1987), consistent with the advanced digestion of fish from chinstrap penguins sampled after overnight trips of $14 \mathrm{~h}$ typical duration. The abrupt change in the state of digestion indicated that the switch in prey occurred during a hiatus in feeding. Wilson (1995) observed peaks in prey ingestion around sunrise and sunset, and a pause in feeding at night, by a chinstrap penguin foraging at King George Island. It may be that success at feeding on myctophids declines through the night, after which the penguins switch solely to krill, perhaps closer to Seal Island, as the morning light increases. Stratification was not observed in stomach contents of diurnal foragers, suggesting they consume krill exclusively and take prey at more regular intervals than those foraging overnight. These scenarios are consistent with patterns in the spatial and temporal distribution of chinstrap penguin prey

A diel vertical migration from depths of 150 to $400 \mathrm{~m}$ during the day to the upper $100 \mathrm{~m}$ at night has been demonstrated in 2 of the 4 myctophid species (Electrona carlsbergi and Krefftichthys anderssoni) taken by penguins in this study (Zasel'sliy et al. 1985, Perissinotto \& McQuaid 1992). These upward migrations of myctophid fish correspond with periods of enhanced feeding of fish on krill near the surface at sunset and just before sunrise (Zasel'sliy et al. 1985 , Podrazhanskaia \& Tarverdieva 1991). Our findings support the view that myctophids move to the surface at dusk and become more vulnerable to chinstrap penguins from Seal Island. Subsequently, penguins stop feeding on fish - probably during the first half of the trip - and begin taking krill exclusively. It is unclear whether the birds are feeding opportunistically on the most available prey species, which changes through the night, or are shifting their focus from fish to krill, perhaps by moving inshore. That myctophids apparently are near the surface until morning (Zasel'sliy et al. 1985) suggests the latter.

Because myctophid fish are primarily meso-epipelagic (Zasel'sliy et al. 1985, Perissinotto \& McQuaid 1992), piscivorous, land-breeding predators can only meet their daily food requirement by traveling extended distances to oceanic areas (e.g. king penguins travel 28 to $1489 \mathrm{~km}$ offshore; Stahl et al. 1985, Adams \& Klages 1987, Kooyman et al. 1992, Jouventin et al. 1994), Consistent with this pattern, a recent study tracking chinstrap penguins to their foraging grounds north of Seal Island showed that birds foraging diurnally remained close to the island, whereas overnight foragers traveled to and beyond the edge of the continental shelf (authors' unpubl. data). For penguins foraging at night, it may be energetically worthwhile to travel far offshore to obtain energy-rich prey (see Obst et al. 1995) that are relatively easy to capture (note that myctophid photophores may be visible to penguins). The least energy-rich myctophid consumed in this study, Gymnoscopelus nicholsi, has 17 and $49 \%$ more energy per unit wet weight than adult gravid female and adult male Antarctic krill, respectively; Electrona species represent a 72 to $120 \%$ energy gain over krill (T. Ichii, National Research Institute of Far Seas Fisheries, 5-7-1 Orido, Shimizu, 424 Japan, unpubl. data; specimens collected near Seal Island during summer 1994/95). Meals obtained overnight were similar in mass to diurnal meals even though overnight foragers spent 30 to $80 \%$ more time in apparently more distant feeding areas. However, considering the reconstructed mass of the fish and their greater energetic value, overnight foragers at least partly covered the additional energetic overhead of longer duration, more distant, trips. Chinstrap penguins at Seal Island that forage overnight may use distant, but profitable, resources (myctophids) to feed themselves, but rely on inshore prey (krill) to provision offspring, as suggested for king penguins (Jouventin et al. 1994, Cherel et al. 1996).

Even though our findings suggest that myctophids are an important source of energy for overnight foragers, all fish remains were probably not retained in the stomach until birds arrived ashore; myctophids are probably eaten at the most distant point of penguins' foraging excursions. Experimental feeding trials on gentoo, little Eudyptula minor, and African penguins suggest that otoliths can be passed from the stomach within 1 to $4 \mathrm{~h}$ after consumption and that 12,58 , and $100 \%$, respectively, may be undetected by lavaging after $16 \mathrm{~h}$ (Wilson et al. 1985, Gales 1987). The contribution of fish to penguin energy budgets may be 
underestimated, especially in populations where trips to sea exceed the time taken to digest fish (e.g. chinstrap penguins at Signy and King George Islands; Lishman 1985, Trivelpiece et al. 1990).

Although chinstrap penguins are considered to be krill specialists (Volkman et al. 1980, Lishman 1985 , Trivelpiece et al. 1990), the daily timing of foraging has rarely been considered. For example, chinstrap penguins in the vicinity of Elephant Island had $96 \%$ Euphausia superba in their stomachs (by weight), with few birds $(7 \%)$ reportedly showing evidence of fish (Croxall \& Furse 1980). At 2 particular sites on Clarence Island, $40 \%$ of the birds were reported to have eaten fish, although it is difficult to assess fish importance because number of otoliths and sampling time were not noted (Croxall \& Furse 1980). Similarly, during 6 breeding seasons at Admiralty Bay, King George Island, stomach sampling indicated that chinstrap penguins relied heavily on krill in all years except one (Jablonski 1985, Trivelpiece et al. 1990). In 1980/81, sampling conducted by Jablonski (1985) indicated that $65 \%$ of chinstrap diet was composed of fish with the remainder being krill (17\%) and amphipods $(5 \%)$. He also showed a greater frequency of fish in the diet of 'morning' $(100 \% ; n=48)$ versus 'evening' $(46 \%$; $\mathrm{n}=49$ ) foragers, which may have resulted from feeding modes similar to those reported here. At Seal Island in 1989/90, fish occurred in chinstrap penguins lavaged before noon 10 times as frequently as those sampled after noon $179 \%(\mathrm{n}=14$ birds) vs $7 \%(\mathrm{n}=26)$, respectively; authors' unpubl. data]. It is clear that while chinstrap penguins at Seal Island rely on krill they do not specialize on krill exclusively, but rather appear to feed on different prey based on temporal and spatial availability. The generality of this finding is unknown; future diet sampling should consider the potential for diel variability in diet composition. Moreover, interpreting the importance of a particular prey to chinstrap penguins through diet sampling requires knowledge of potential foraging strategies and factors influencing the relative frequency of those behaviors within and between years. For instance, this study suggests that shifts in diurnal trip duration, which could be affected by krill availability, can influence the relative occurrence of foraging at night, when feeding behavior may be redirected toward myctophids.

\section{Conclusions and implications}

Penguins at Seal Island may be faced with the necessity of feeding at night, when limited vision may hamper prey detection, because of 2 particular constraints on chick survival: chicks must grow at an adequate rate, and mates must coordinate feeding routines so that small chicks are continuously attended. The former requires the regular acquisition of food and the latter restricts the decision about when (and apparently where) to acquire it. Although birds may not prefer evening departures, the regularity of overnight foraging at Seal Island suggests that these trips are necessary to maintain the timely delivery of food to chicks when a meal might otherwise be missed. Even though birds have apparently adapted to a nocturnal habit at sea, penguins avoided transiting the island's coastline under darkness and foraged more frequently by day when permitted by shorter diurnal trip durations (of their mates). These findings suggest that darkness could restrict visually-based movement and feeding. A behavioral adjustment countering the apparent costs of nocturnal foraging is for parents to embark on longer, more distant foraging trips to pursue energy-rich bioluminescing myctophid fish.

This study demonstrates the need to consider photoperiodicity when examining penguin foraging behavior. Diel changes in light intensity apparently compel chinstrap penguins to use feeding modes that differ in diet and duration. These distinct modes reveal complex interactions between foraging performance, prey availability, and the physical environment. Because light intensity affects such fundamental aspects as predators' visual range and prey distribution, similarly complex interactions can be expected in other studies of visual predators and their prey.

Acknowledgements. We thank members of the field teams, including Don Croll, Mike Goebel, Lisa Hiruki, William Meyer, Steve Osmek, Mike Schwartz, and Brian Walker for help in establishing field protocols, enthusiastic data collection, and for many helpful discussions. Many of the ideas presented here were conceived through discussions with the senior author's (J.K.J.) thesis committee at the University of Oregon's Institute of Marine Biology, and we especially thank Jan Hodder for her insightful contributions. We are also grateful to Jason Baker, Lisa Hiruki, Harriet Huber, Gerald Kooyman, Robert Russell, Mike Schwartz and 3 anonymous reviewers for valuable comments on earlier drafts. Steve Osmek conducted the diet analyses that produced the unpublished results for 1990. Taro Ichii of Japan's National Research Institute of Far Seas Fisheries helped in identifying fish otoliths. Thanks are also extended to the officers and crew of the NOAA ship 'Surveyor' and the MV 'Explorer' for exceptional logistical. support. This research was supported by the National Oceanic and Atmospheric Administration, National Marine Fisheries Service, as part of its Antarctic Marine Living Resources Program.

\section{LITERATURE CITED}

Adams NJ, Klages NT (1987) Seasonal variation in the diet of the king penguin (Aptenodytes patagonicus) at subantarctic Marion Island. J Zool Soc Lond 212:303-324

Ainley DG (1972) Flocking in Adélie Penguins. Ibis 114: $388-390$ 
Aksnes DL, Giske J (1993) A theoretical model of aquatic visual feeding. Ecol Model 67:233-250

Bannasch R, Wilson RP, Culik B (1994) Hydrodynamic aspects of design and attachment of a back-mounted device in penguins. J Exp Biol 194:83-96

Bengtson JL, Croll DA, Goebel ME (1993) Diving behavior of chinstrap penguins at Seal Island. Antarct Sci 5:9-15

Bowmaker JK, Martin GR (1985) Visual pigments and oil droplets in the penguin, Spheniscus humboldti. J Comp Physiol A 156:71-77

Broni SC (1985) Social and spatial foraging patterns of the jackass penguin Spheniscus demersus. S Afr J Zool 20: $241-245$

Brooke M (1990) The Manx Shearwater. Poyser, London

Brown CR (1986) Cliff swallow colonies as information centers. Science 234:83-85

Chappell MA, Janes DN, Shoemaker VH, Bucher TL, Maloney SK (1993) Reproductive effort in Adélie penguins. Behav Ecol Sociobiol 33:173-182

Cherel Y, Ridoux V, Rodhouse PG (1996) Fish and squid in the diet of king penguin chicks, Aptenodytes patagonicus, during winter at sub-antarctic Crozet Islands. Mar Biol 126:559-570

Cockrem JF (1990) Circadian rhythms in Antarctic penguins In: Darby J, Davis LS (eds) Penguin biology. Academic Press, Orlando, FL, p 319-344

Conroy JWH, White MG, Furse JR, Bruce G (1975) Observations on the breeding biology of the chinstrap penguin, Pygoscelis antarctica, at Elephant Island, South Shetland Islands. Br Antarct Surv Bull 40:23-32

Croll DA, Jansen JK, Goebel ME, Boveng PL, Bengtson JL (1996) Foraging behavior and reproductive success in chinstrap penguins: the effects of transmitter attachment. $J$ Field Ornithol 67:1-9

Croxall JP, Davis RW, O'Connell MJ (1988) Diving patterns in relation to diet of gentoo and macaroni penguins at South Georgia. Condor 90:157-167

Croxall JP, Furse JR (1980) Food of chinstrap penguins Pygoscelis antarctica and macaroni penguins Eudyptes chrysolophus at Elephant [sland, South Shetland Islands. Ibis $122: 237-245$

Culik B, Bannasch R, Wilson RP (1994) Extermal devices on penguins: how important is shape? Mar Biol 118:353-357

Emlen JT, Penney RL (1966) The navigation of penguins. Sci Am 215:104-113

Everson I (1982) Diurnal variations in mean volume backscattering strength of an Antarctic krill (Euphausia superba) patch. J Plankton Res 4:155-162

Everson I, Murphy E (1987) Mesoscale variability in the distribution of krill Euphausia superba. Mar Ecol Prog Ser $40: 53-60$

Fite KV (1973) Anatomical and behavioral correlates of visual acuity in the great horned owl. Vision Res 13:219-230

Gales RP (1987) Validation of the stomach-flushing technique for obtaining stomach contents of penguins. Ibis 129: $335-343$

Golombek DA, Calcagno JA, Luquet CM (1991) Circadian activity rhythm of the chinstrap penguin of Isla Media Luna, South Shetland Islands, Argentine Antarctica. J Field Ornithol 62:293-298

Grubb TC (1974) Olfactory navigation to the nesting burrow in Leach's Petrel (Oceanodroma leucorrhoa). Anim Behav 22:192-202

Hair JF, Anderson RE, Tatham RL, Black WC (1992) Multivariate data analysis. Macmillan, New York

Hofman RJ, Reichle RA, Siniff DB, Müller-Schwarze D (1974) The leopard seal (Hydrurga leptonyx) at Palmer Station,
Antarctica. In: Llano GA (ed) Adaptations within Antarctic ecosystems. Smithsonian Institute, Washington, DC, p $769-782$

Jablonski B (1985) The diet of penguins on King George Island, South Shetland Islands. Acta Zool Cracov 29:117-186

Jansen JK (1996) Ecological constraints on chinstrap penguin. foraging behavior: the role of diel and seasonal light changes. Master's thesis, University of Oregon, Eugene

Jouventin P, Capdeville D, Cuenot-Chaillet F, Boiteau C (1994) Exploitation of pelagic resources by a non-flying seabird: satellite tracking of the king penguin throughout the breeding cycle. Mar Ecol Prog Ser 106:11-19

Kalinowski J, Witek Z (1980) Diurnal vertical distribution of krill aggregations in the Western Antarctic. Pol Polar Res $1: 127-146$

Kirkwood R, Robertson G (1997) The foraging ecology of female emperor penguins in winter. Ecol Monogr 67: $155-176$

Kooyman GL, Cherel Y, Le Maho Y, Croxall JP, Thorson PH, Ridoux V. Kooyman CA (1992) Diving behavior and energetics during foraging cycles in king penguins. Ecol Monogr 63:143-163

Lishman GS (1985) The food and feeding ecology of Adélie (Pygoscelis adeliae) and chinstrap penguins ( $P$. antarctica) at Signy Island, South Orkney Islands. J Zool Lond A 205:245-263

Martin GR (1986) Sensory capacity and the nocturnal habit in owls. Ibis 128:266-277

Martin GR (1990a) Birds by night. Poyser, London

Martin GR (1990b) The visual problems of nocturnal migration. In: Gwinner E (ed) Bird migration: the physiology and ecophysiology. Springer-Verlag, Berlin, p 186-197

Martin GR, Young SR (1984) The eye of the humboldt penguin, Spheniscus humboldti: visual fields and schematic optics. Proc R Soc Lond B 223:197-222

Meyer WR, Bengtson JL, Jansen JK, Russell RW (1997) Relationships between brood size and parental provisioning performance in chinstrap penguins during the chick guard phase. Polar Biol 17:228-234

Miller GDM, Hampton I (1989) Krill aggregation characteristics: spatial distribution patterns from hydroacoustic observations. Polar Biol 10:125-134

Moore FR (1987) Integration of environmental stimuli in the migratory orientation of the savannah sparrow (Passerculus sandwichensis). Anim Behav 33:657-663

Müller-Schwarze D (1971) Behavior of Antarctic penguins and seals. In: Quam LO (ed) Research in the Antarctic. American Association for the Advancement of Science, Washington, DC, p 250-276

Müller-Schwarze D (1984) The behavior of penguins. State University of New York Press, Albany

Müller-Schwarze D, Müller-Schwarze C (1975) Relations be. tween leopard seals and Adélie penguins. Rapp Pv Réun Cons Int Explor Mer 169:394-404

Nevitt GA, Veit RR, Kareiva P (1995) Dimethyl sulphide as a foraging cue for Antarctic procellariiform seabirds. Nature 376:680-682

Norman Fl, Ward SJ (1993) Foraging group size and dive duration of Adélie penguins Pygoscelis adeliae at sea off Hop Island, Rauer Group. East Antarctica. Mar Ornithol $21: 37-47$

Obst BS, Russell RW, Hunt GL, Eppley ZA, Harrison NM (1995) Foraging radii and energetics of least auklets (Aethia pusilla) breeding on three Bering Sea islands. Physiol Zool 68:647-672

Penney RL, Lowry G (1967) Leopard seal predation on Adélie penguins. Ecology 48:878-882 
Perissinotto R, McQuaid CD (1992) Land-based predator impact on vertically migrating zooplankton and micronecton advected to a Southern Ocean archipelago. Mar Ecol Prog Ser 80:15-27

Podrazhanskaia SG, Tarverdieva MI (1991) Electrona carlsbergi Taning feeding pattern in different areas of the Southern Ocean. In: Maslennikov VV (ed) Electrona carls. bergi in the South Polar Frontal zone, Vol 2, Biological aspects of life and distribution. Vsesoiuznyi nauchnoissledovatel'skii institut morskogo rybnogo khoziaistva i okeanografii (VNIRO), Moscow, p 73-84

Presti DE (1985) Avian navigation, geomagnetic field sensitivity, and biogenic magnetite. In: Kirschvink JL, Jones $\mathrm{S}$, MacFadden BJ (eds) Magnetite biomineralization and magnetoreception in organisms. Plenum, New York, p 455

Pütz K, Bost CA (1994) Feeding behavior of free-ranging king penguins (Aptenodytes patagonicus). Ecology 75:489-497

Ringelberg $\mathrm{J}$ (1995) Changes in light intensity and diel vertical migration: a comparison of marine and freshwater environments. J Mar Biol Assoc UK 75:15-25

Rogers T, Bryden MM (1995) Predation of Adélie penguins (Pygoscelis adeliae) by leopard seals (Hydrurga leptonyx) in Prydz Bay, Antarctica. Can J Zool 73:1001-1004

Schreer JF, Testa JW (1995) Statistical classification of diving behavior. Mar Mamm Sci 11:85--93

Scolaro JA, Suburo AM (1994) Timing and duration of foraqing trips in Maqellanic penquins. Mar Ornithol 22: $231-235$

Snyder AW, Laughlin SB, Stavenga DG (1977) Information capacity of eyes. Vision Res 17:1163-1175

SPSS Inc. (1993) SPSS base system user's guide, release 6.0. SPSS Inc, Chicago

Stahl JC, Jouventin P, Mougin JL, Roux JP, Weimerskirch H (1985) The foraging zones of seabirds in the Crozet Islands sector of the Southern Ocean. In: Siegfried WR, Condy PR, Laws RM (eds) Antarctic nutrient cycles and food webs. Springer-Verlag, Berlin, p 478-485

Trivelpiece $W Z$, Bengtson $J L$, Trivelpiece SG, Volkman NJ (1986) Foraging behavior of gentoo and chinstrap penguins as determined by new radiotelemetry techniques. Auk 103:777-781

Trivelpiece WZ, Trivelpiece SG, Geupel GR, Kjelmyr J, Volkman NJ (1990) Adélie and chinstrap penguins: their potential as monitors of the Southern Ocean marine ecosystem. In: Kerry KR, Hempel G (eds) Antarctic ecosystems: ecological change and conservation. SpringerVerlag, Berlin, p 191-202

Verheyden C, Jouventin P (1994) Olfactory behavior of foraging procellariiforms. Auk 111:285-291

Volkman NJ, Presler P, Trivelpiece WZ (1980) Diets of pygoscelid penguins at King George Island, Antarctica. Condor 82:373-378

Editorial responsibility: Otto Kinne (Editor), Oldendorf/Luhe, Germany
Ward P, Zahavi A (1973) The importance of certain assemblages of birds as 'information-centres' for food-finding. Ibis 115:517-534

Weimerskirch $\mathrm{H}$, Wilson RP (1992) When do wandering albatrosses Diomedea exulans forage? Mar Ecol Prog Ser 86 : 297-300

Williams TD, Rothery P (1990) Factors affecting variation in foraging and activity patterns of gentoo penguins (Pygoscelis papua) during the breeding season at Bird Island, South Georgia. J Appl Ecol 27:1042-1054

Wilson RP (1984) An improved stomach pump for penguins and other seabirds. J Field Omithol 55:109-112

Wilson RP (1985) Diurnal foraging patterns of the jackass penguin. Ostrich 56:212-214

Wilson RP (1995) Foraging ecology. In: Williams TD (ed) The penguins. Oxford University Press, Oxford, p 81-106

Wilson RP, Bost CA, Pütz K, Charrassin JB, Culik BM, Adelung D (1997) Southern rockhopper penguin Eudyptes chrysocome chrysocome foraging at Possession Island. Polar Biol 17:323-329

Wilson RP, Culik B, Coria NR, Adelung D, Spairani HJ (1989) Foraging rhythms in Adélie penguins ( $p_{Y \text { goscelis adeliae) }}$ at Hope Bay, Antarctica; determination and control. Polar Biol 10:161-165

Wilson RP, Grant WS, Duffy DC (1986b) Recording devices on free-ranging marine animals: does measurement affect foraging performance? Ecolngy 67.1091-109.3

Wilson RP, La Cock GD, Wilson MP, Mollagee F (1985) Differential digestion of fish and squid by jackass penguins. Ornis Scand 16:77

Wilson RP, Puetz K, Bost CA, Culik B, Bannasch R, Reins T, Adelung $D$ (1993) Diel dive depth in penguins in relation to diel vertical migration of prey: whose dinner by candlelight? Mar Ecol Prog Ser 94:101-104

Wilson RP, Wilson MPT (1990) Foraging ecology of breeding Spheniscus penguins. In: Davis LS, Darby J (eds) Penguin biology. Academic Press, New York, p 181-206

Wilson RP, Wilson MPT (1995) The foraging behaviour of the African penguin Spheniscus demersus. In: Dann P, Norman I, Reilly P (eds) The penguins: ecology and management. Surrey Beatty \& Sons Pty Ltd, Chipping Norton, NSW, p 244-265

Wilson RP, Wilson MPT, McQuaid L (1986a) Group size in foraging African penguins (Spheniscus demersus). Ethology $72: 338-341$

Yeates GW (1971) Diurnal activity in the Adélie penguin (Pygoscelis adeliae) at Cape Royds, Antarctica. J Nat Hist 5:103-112

Zasel'sliy VS, Kudrin BD, Poletayev VA, Chechenin SC (1985) Some features of the biology of Electrona carlsbergi (Taning) (Myctophidae) in the Atlantic sector of the Antarctic. J Ichthyol 25:163-166

Submitted: September 25, 1997; Accepted: February 13, 1998 Proofs received from author(s): April 20,1998 